Ocean Modelling

August 2016, Volume 104, Pages 99-110

http://dx.doi.org/10.1016/i.ocemod.2016.05.001

http://archimer.ifremer.fr/doc/00335/44579/

(C) 2016 Elsevier Ltd. All rights reserved.

\title{
Antarctic icebergs melt over the Southern Ocean : climatology and impact on sea ice
}

\author{
Merino Nacho ${ }^{1,2,{ }^{*}}$, Le Sommer Julien ${ }^{1,2}$, Durand Gael ${ }^{1,2}$, Jourdain Nicolas C. ${ }^{1,2}$, Madec Gurvan ${ }^{3,4}$, \\ Mathiot Pierre ${ }^{5}$, Tournadre Jean ${ }^{6}$
}

${ }^{1}$ CNRS, LGGE, F-38041 Grenoble, France

${ }^{2}$ Univ. Grenoble Alpes, LGGE, F-38041 Grenoble, France

${ }^{3}$ LOCEAN, CNRS/MNHN/IRD/UPMC, Paris, France

${ }^{4}$ NOC, Southampton, UK

${ }^{5}$ Met Office, Exeter, UK

${ }^{6}$ LOS, IFREMER, Brest, France

* Corresponding author : Nacho Merino, email addresses : ignacio.merino.cue@gmail.com ; ignacio.merino@lgge.obs.ujf-grenoble.fr

\begin{abstract}
:
Recent increase in Antarctic freshwater release to the Southern Ocean is suggested to contribute to change in water masses and sea ice. However, climate models differ in their representation of the freshwater sources. Recent improvements in altimetry-based detection of small icebergs and in estimates of the mass loss of Antarctica may help better constrain the values of Antarctic freshwater releases. We propose a model-based seasonal climatology of iceberg melt over the Southern Ocean using state-of-the-art observed glaciological estimates of the Antarctic mass loss. An improved version of a Lagrangian iceberg model is coupled with a global, eddy-permitting ocean/sea ice model and compared to small icebergs observations. Iceberg melt increases sea ice cover, about $10 \%$ in annual mean sea ice volume, and decreases sea surface temperature over most of the Southern Ocean, but with distinctive regional patterns. Our results underline the importance of improving the representation of Antarctic freshwater sources. This can be achieved by forcing ocean/sea ice models with a climatological iceberg fresh-water flux.
\end{abstract}

\section{Highlights}

- H1: The Antarctic iceberg freshwater flux is estimated with a sea ice/ocean/iceberg model $\rightarrow \mathrm{H} 2$ : Including vertical profiles of ocean currents improves modelled iceberg trajectories $>\mathrm{H} 3$ : The iceberg model overall reproduces the observed probability of iceberg presence. $\mathrm{H} 4$ : Iceberg meltwater increases sea ice formation with few local deviations. H5: A climatology of iceberg freshwater flux is offered to be used in climate models 
Keywords : Icebergs, Southern Ocean, Sea ice, Freshwater fluxes

\section{List of figures and supplementary files captions}

Figure1: Modelled ocean temperatures of the last year of a 20-years ORCA025 simulation coupled with the NEMO-ICB module. (a) Sea Surface Temperature. (b) Averaged temperature over the first $150 \mathrm{~m}$ from the surface.

Figure2: 5 Examples of trajectories of modelled icebergs. (a) Trajectories of $73 \mathrm{~m}$-thick icebergs of class number 2 with their corresponding sources points (see Supplementary Material); (b) Trajectories of 133 m-thick icebergs of class 
number 3 and the name of relevant sectors. Red dots correspond to trajectories only considering the drag exerted by the ocean surface, and blue dots correspond 10 to icebergs considering the vertical integrated ocean drag.

Figure3: Sea ice concentration means for: (a) Summer in model results, (b) summer from observations, (c) winter in model results, and (d) winter from observations. Summer means include months from October to March. Winter means includes months from April to September. Model results correspond to

15 ICBT (simulation with explicit icebergs) monthly means of the first 5 years after the 9-year spin up. Observations correspond to the National Snow and Ice Data Center (NSDIC) (Peng et al., 2013) sea ice concentration climatology of the period 1979-2010. Concentrations lower than $10 \%$ are not show.

Figure4: Standard deviation of the yearly mean sea ice concentration for the first 5 years after the 9-year spin up of ICBT (simulation with explicit icebergs).

Figure5: Probability of iceberg detection in a $100 \mathrm{~km} \times 100 \mathrm{~km}$ grid cell during a year. (a) Observations from ALTIBERG database (Tournadre J., 2015), (b) Model results. Points where annual mean sea ice cover is larger than $40 \%$ are shaded.

$25 \quad$ Figure6: Climatology of iceberg freshwater flux over the Southern Ocean in $\mathrm{mm} /$ day for (a) summer, (b) autumn, (c) winter and (d) spring seasons. The flux is computed from 11 years of ICBT (simulation with explicit icebergs) after 9 years of spin-up.

Figure7: Spatial and monthly Integration of the iceberg freshwater fluxes 30 per Southern Ocean sector. Dashed lines correspond to annual means. Red, green, blue and black lines correspond to Atlantic, Indian, Pacific and global sectors respectively

Figure8: (a) Anomalous sea ice concentration in ICBT (simulation with explicit icebergs) versus CTR (simulation without icebergs fluxes).. (b) Anoma-

35 lous sea ice thickness in ICBT versus CTR.. Results are computed from sea ice monthly means obtained for the first 5 years of simulations after the 9 -years spin-up

Figure9: Climatological seasonal cycles of sea ice volume in ICBT (simulation with explicit icebergs) (solid line) and CTR (simulation without icebergs

40 fluxes) (dashed line), for all the Southern Ocean, Atlantic, Pacific, Indian and Bellingshausen Sea sectors respectively.

Figure10: (a) Anomalous sea ice concentration in ICBT (simulation with explicit icebergs) versus CLIM (simulation forced with icebergs fluxes) . (b) Anomalbus sea ice thickness in ICBT versus CLIM. Results are computed from sea ice monthly means obtained for the first 5 years of simulations after the 9-years spin-up

Figure11: Mean sea surface temperature difference between ICBT (simulation with explicit icebergs) and CTR (simulation without icebergs fluxes) simulations averaged over January, February and March of the first five years of the simulation after spin-up. This plot shows the cold temperature anomaly in the seasonal ice zone in the Weddell and the warm temperature anomaly west of the Antarctic Peninsula.

Supplementary file Iceberg-Source-Points-Merino.xls: Distribution of iceberg 
source points along the model coastline. The table provides the longitude, 55 latitude and calving rate (in Gt/year) corresponding to each iceberg source point of the iceberg model. Calving rates for each ice-shelf and oceanic sector are extracted from Depoorter et al. (2013) and distributed along the corresponding ice-shelf and sector coastline on NEMO ORCA025 grid.

Supplementary file Iceberg-Climatology-Merino.nc : Monthly climatology of

60 iceberg meltwater flux. Monthly means are computed using the last 11 years of ICBT (simulation without icebergs fluxes) after the spin-up period. The NetCDF file contains the longitude, the latitude and the freshwater flux for each grid cell and month.

\section{Introduction}

65 In contrast with the rapid sea ice loss observed in the Arctic, satellite observations show a slight overall increase in sea ice extent (SIE) around Antarctica in recent decades (Comiso and Nishio, 2008; Parkinson and Cavalieri, 2012). The overall increase in SIE results from the integration of large regional increases and decreases in sea ice concentration (SIC) around Antarctica (Turner et al.,

70 2009). While the amplitude of overall trend is open to debate, the geographical pattern of regional changes in SIC has been clearly detected in satellite observations (Eisenman et al., 2014). The mechanisms driving overall change in Antarctic sea ice and its regional pattern are also not fully understood as climate models generally fail to simulate these trends in a rigorous manner (Polvani and

75 Smith, 2013; Gagne et al., 2015, Turner et al., 2015). Whether this is indicative of a poor representation of physical processes in climate models, for instance the modelled ice drift (Uotila et al., 2014), or reflects the fact that the observed trend in SIE results from natural variability is still unclear.

Several model and observational studies have investigated the causes of

80 the increase in Antarctic SIE observed over recent decades. Proposed external drivers for such change include winds, air-temperature, precipitation and freshwater forcing (FWF) from Antarctica. Model experiments show that the changes in surface winds and air temperature associated with a positive trend in the Southern Annular Mode contribute to regional changes in Antarctic SIC

85 with a spatial pattern similar to the observed trends (Lefebvre et al., 2004). The role of changing winds appears to be dominant in the regional response to changing atmospheric conditions around Antarctica, through a combination of changes in wind-driven advection of sea ice and wind-driven thermodynamic changes (Holland and Kwok, 2012; Fan et al., 2014; Holland et al., 2014). However, changes in winds do not appear to quantitatively account for all the changes observed in SIE (Liu et al., 2004; Fan et al., 2014). Changes in Antarctic SIE may also involve ice-ocean feedback (Zhang, 2007; Goosse and Zunz, 2014) and ice-atmosphere feedback (Stammerjohn et al., 2008).

It has also been suggested that the increase in Antarctic SIE may be due in

95 part to changes in freshwater release from the Antarctic Ice sheet (AIS) (Bintanja et al., 2013; Swart and Fyfe, 2013). This hypothesis is consistent with the 
observed acceleration of the mass loss from the AIS (Shepherd et al., 2012; Rignot et al., 2008). The oceanic response mechanism involves freshwater-induced changes in ocean surface stratification and convection regimes (Marsland and 100 Wolff, 2001). However, to date, there is no quantitative agreement among existing model studies regarding the impact of the accelerated mass loss from the AIS on Antarctic sea ice. This discrepancy is arguably due to the different and crude representations of freshwater forcing from AIS in ocean models.

The oceanic freshwater forcing from AIS combines the contributions of basal melt in ice-shelf cavities around Antarctica and freshwater fluxes due to melting icebergs over the Southern Ocean. While the input of freshwater due to basal melt occurs at the base of each ice-shelf, icebergs are calved at ice-shelf fronts and melt progressively as they are transported northwards over the Southern Ocean. Reliable estimates of present-day sub ice-shelf melt and calying rates are now available for each ice-shelf (Depoorter et al., 2013; Rignot et al., 2013). However, the redistribution of iceberg mass over the Southern Ocean remains imperfectly constrained, so that ocean model studies differ in their representation of iceberg melt over the Southern Ocean (Bintanja et al., 2013; Swart and Fyfe, 2013; van den Berk and Drijfhout, 2014).

Over the last decade, observations of iceberg distribution and melt rate have mostly been limited to the tracking of large tabular icebergs (i.e. longer than $18 \mathrm{~km}$ ) (Silva et al., 2006). Recent methods based on radar altimetry make it possible to estimate the distribution of the annual mean volume of icebergs and the annual mean melt rates associated with smaller icebergs (up to about $3 \mathrm{~km}$ 120 in length) (Tournadre J., 2015). However, accurate estimates of the seasonal and spatial distribution of iceberg melt rates are still not possible because it would require tracking individualicebergs to determine where freshwater release actually occurs. In addition, the altimeter detection of icebergs is limited to sea ice free water and by constraints due to satellite orbits over the southernmost

125 latitudes. Alternatively, explicit iceberg models based on a Lagrangian representation of collections of icebergs have also been proposed as an alternative for estimating freshwater releases from icebergs over the Southern Ocean (Bigg et al., 1997; Gladstone et al., 2001). A widely used climatology of Antarctic iceberg freshwater fluxes, proposed by Silva et al. (2006), combines observations of large tabular icebergs and modelling of small icebergs.

Several Lagrangian iceberg models have recently been coupled with ocean circulation models at various grid resolutions (Martin and Adcroft, 2010; Jongma et al., 2009; Marsh et al., 2015). These models, however, do not yet use the most up-to-date estimates of calving rates (Depoorter et al., 2013; Rignot et al., 2013). Moreover, modelled iceberg distributions have not yet been systematically compared with observations from radar altimetry. Tournadre et al. (2012) also suggest that existing models might not be able to adequately represent iceberg trajectories across Southern Ocean subpolar gyres (especially in the Weddell Gyre). This may be due to biases in current Lagrangian iceberg models, which are driven by ocean surface fields, or to the coarse resolution of most ocean circulation models coupled with iceberg models.

In this paper, we propose a model-based estimate of iceberg melt over the 
Southern Ocean and study the impact of iceberg melt on ocean surface properties and sea ice. The estimate is obtained with an improved version of a Lagrangian iceberg model coupled with an eddy-permitting ocean-sea ice model, using the most recent input calving rates based on glaciological studies. The modelled iceberg distribution is shown to compare favourably with observations in most of the Southern Ocean sectors. We show the strong seasonality of iceberg freshwater releases over the Southern Ocean and discuss its impact on

${ }_{150}$ Antarctic sea ice. We further show that the impact of icebergs on Antarctic sea ice can be reproduced, to a large extent, by forcing the ocean-sea ice model with a climatological iceberg freshwater flux (provided as Supplementary Materialy). The methods are described in section 2. The modelled distribution of icebergs is presented and compared with observations in section 3. The impact of iceberg

155 freshwater release on sea ice is discussed in section 4. Finally, section 5 draws conclusions and discusses the proposed climatology of iceberg freshwater fluxes.

\section{Material and methods}

The distribution of freshwater fluxes due to icebergs is estimated here with an interactive ocean/sea ice/iceberg model forced with recent estimates of Antarctic freshwater forcing. In this section we describe the details of the model set up and the different datasets used to perform this work.

\subsection{Ocean/sea ice model configuration}

The ocean simulation is based on NEMO v 3.5 (Madec, 2014). The model configuration uses a 0.25 -degree resolution grid (ORCA025) with 75 vertical levels developed and maintamed by the DRAKKAR group. Ice-shelf cavities are not explicitly represented in the model, but ice-shelf meltwater is prescribed (see section 2.3). The ocean component is coupled with the LIM2 sea ice model (Fichefet and Morales Maqueda, 1997) and the NEMO iceberg module (Marsh et al., 2015) (see section 2.2 ). The ocean model is forced by using core bulk formulae with a climatological repeated-year atmospheric forcing based on ERA-Interim (Dee et al., 2011). The climatological repeated-year forcing is constructed following the same approach as Grégorio et al. (2015) itself based on Penduff et al (2011). This forcing is built by computing 365 ERA-Interim daily ayerages for the period 1979-2011. The resulting atmospherical forcing is com175 posed of the daily averages of precipitations, runoff, cloud cover, long and short wave radiation, 10 meters winds, temperature and air humidity. In addition quadratic contributions are added to air-sea fluxes in order to account for the contribution of non-linear high frequency correlations in bulk formulae. A sea surface salinity restoring towards NODC WOA94 data, with a piston velocity (Griffies et al., 2009) of $50 \mathrm{~m} / 300$ days, is applied, except at the first coastal grid points. This is commonly practised in stand-alone ocean/sea ice DRAKKAR simulations in order to not affect the total coastal runoff in the simulations. 


\subsection{Standard NEMO-ICB and new features in NEMO-ICB}

The ocean component is coupled with the NEMO-ICB iceberg module (Marsh et al., 2015). It describes the evolution of an ensemble of Lagrangian particles. Each Lagrangian particle is meant to represent a collection of one or several icebergs. Each collection of icebergs belongs to one of the ten different size categories of the statistical distribution based on ship observations proposed by Gladstone et al. (2001). By simplicity, a constant upper bound of $250 \mathrm{~m}$ is considered for all the ice shelves in this study, consistently with Martin and Adcroft (2010) and Marsh et al. (2015). This upper bound corresponds to the typical thickness of ice-shelves at their calving front. NEMO-ICB considers a fixed number of source points with constant in time iceberg production rate for each individual source location. The dynamics and thermodynamics of each collec195 tion of icebergs are prescribed according to the procedure used by Marsh et al. (2015), which mostly follows Martin and Adcroft (2010). Freshwater fluxes to the ocean model are calculated at each time-step from the iceberg melt rate and injected at the ocean surface. However, in the present version of NEMO-ICB, heat fluxes from icebergs are not applied to the ocean model: neither sensible heat fluxes due to iceberg-ocean temperature difference, nor latent heat of fusion when melting are taken into account.

As is common in iceberg models, the model only describes the evolution of small icebergs (up to $2.2 \mathrm{~km}$ in length). This choice is supported by the findings of Tournadre et al. (2015) indicating that the melting of large icebergs provides only a marginal contribution to total iceberg freshwater fluxes.

\subsubsection{NEMO-ICB module modifications}

Unlike previous versions of Lagrangian iceberg models (Bigg et al., 1997; Gladstone et al., 2001; Martin and Adcroft, 2010), the model used here (NEMOICB module, including the modifications described in section 4 of Marsh et al., 2015) takes into account the influence of the vertical profiles of ocean currents and temperatures instead of only considering the SST and surface ocean velocities, and considers a parametrised interaction with shallow bathymetry. Those modifications (firstly implemented for this work) are described in this section and are found to significantly improve the representation of iceberg trajectories 215 across Southern Ocean subpolar gyres (see section 2.2.2).

The first modification introduced in NEMO-ICB is the vertical integration of ocean currents that takes into account the drag exerted by the entire ocean column in contact with the iceberg, instead of the drag exerted by the ocean surface. This modification allows in particular to take into account the change in the orientation of wind driven currents with depth in the Ekman layer, which is approximately $100 \mathrm{~m}$ deep in the Southern Ocean (Lenn and Chereskin, 2009).

The second modification is the computation of melt rates using ocean temperatures at varying depths, thus taking into account the strong vertical temperature gradients in summer in the upper Southern Ocean. Modelled icebergs, 225 according to observations, can be up to $250 \mathrm{~m}$ thick (Gladstone et al., 2001) and the ocean temperature profiles across the pycnocline in summer can be remark- 
ably abrupt in shallow mixed layers. As shown in Figure 1, surface temperatures and first depth averaged temperatures over 0-150m can differ significantly in some regions.

The last modification introduced in this work is the parametrization of iceberg interaction with bathymetry. With the inclusion of the vertical integration of the ocean currents, the interaction of thick icebergs with shallow bathymetry needs to be explicitly taken into account. This is because, accounting for the ocean drag is needed when a thick iceberg crosses a shallow bathymetry grid cell. We choose not to stop icebergs in shallow regions because the subgrid scale bathymetry probably matters more than the model bathymetry. Nonetheless, we calculate the vertically-averaged velocity over the entire iceberg thickness, with zero velocities at depth where the iceberg is deeper than the model bathymetry, so icebergs are slowed in shallow regions (see equation/ 1 in Appendix). By including this interaction in the model, thick icebergs tend to stay longer in specific coastal regions instead of escaping northwards as it happened in previous versions of the iceberg model. This overall behaviour is in better agreement with observations which indicate the existence of regions with high iceberg presence due to the grounding of thick ones (Jacka and Giles, 2007).

\subsubsection{Impact of vertical shear on simulated iceberg trajectories}

As described in section 2.2.1 the iceberg model used in this study considers ocean currents averaged over the thickness of each iceberg in the drag formulation, instead of the ocean surface currents as commonly applied in previous iceberg modelling studies.

Figure 2 shows the sensitivity to this modification for individual iceberg trajectories departing from different locations and for two different size classes. Icebergs of category \#1 and \#2 (40m and 67m thickness respectively, Gladstone et al. (2001)) are thinner than the typical thickness of the Ekman layer and are therefore not significantly affected by the modification in NEMO-ICB (Figure

255 2a). By contrast, larger and thicker icebergs can only cross the Weddell, Ross, and Amery Seas if the vertical integration of ocean velocities is included in NEMO-ICB (Figure 2b). Icebergs following the Antarctic Coastal Current are more likely to escape before reaching the Antarctic Peninsula and to the north of the Weddell Sea. Consequently, our modification leads to a reduced presence of modelled icébergs in the Atlantic sector, and contributes to better distribute the iceberg mass between Atlantic, Indian and Pacific sectors.

\subsection{Observation-based calving and meltwater input fluxes}

The recent estimate of Antarctic freshwater forcing from Depoorter et al. (2013) is used in our simulations. Depoorter et al. (2013) provide calving rates and basal melt fluxes for 31 ice-shelves around Antarctica. The total observed mass loss from Antarctica is completed with an additional residual flux for each Southern Ocean sector. Both the calving rates and the basal melt rates are in good agreement with another recent observational study (Rignot et al., 2013).

These recent estimates provide a major improvement over the Antarctic 270 freshwater forcings used in previous studies (eg. van den Berk and Drijfhout, 
2014). Indeed, the most recent estimates (Depoorter et al., 2013; Rignot et al., 2013) account for the observed changes in ice-shelf thickness and surface mass balance, in contrast with earlier studies (eg. Rignot and Jacobs, 2002). In addition, improved techniques for grounding line detection, thickness measurements and firn model corrections have been applied to the treatment of the most recent data (between 1994 and 2009) (Depoorter et al., 2013).

Basal melt underneath ice-shelves is prescribed as coastal run-off in our simulation set-up. Following Depoorter et al. (2013), it accounts for 1454 Gt/yr and is distributed at the ice-shelf fronts. The corresponding freshwater flux is applied at ocean grid points lying at the front of each ice-shelf and spread vertically between the base of the calving front and the minimum between the grounding line depth and the bathymetry at the calving front. The $1350 \mathrm{Gt} / \mathrm{yr}$ of calving fluxes estimated in Depoorter et al. (2013) are used as input for the NEMO-ICB module. The iceberg model then generates icebergs, which eventually distribute freshwater at the ocean surface when they melt. Calving rates are kept constant over time and their spatial distribution follows Depoorter et al. (2013). The distribution of source points for iceberg calving is provided in Supplementary Material.

\subsection{Model experiments}

Three experiments based on the described model set up have been run in this work. The iceberg test run (hereafter referred to as ICBT) uses the ocean/sea ice model configuration coupled with the iceberg model described above in section 2.2 in a 20 -year simulation. The ICBT simulation initial state is free of icebergs. The first 9 years of ICBT simulation correspond to the spin-up required for the

295 iceberg model. In steady state after the spin-up, the calving mass input matches the melted iceberg mass. In contrast, in the control run (hereafter CTR), the iceberg model is switched off, and consequently, the ocean/sea ice model does not include any flux from icebergs. CTR is computed for 14 years, that correspond to 9 years of spin-up and 5 years for results comparison with ICBT

300 results. Considering the constant climatological atmospheric forcing applied, the reduced ocean/sea ice model variability allows 5-years means comparisons between both simulations. An extra simulation of 14 years (hereafter CLIM) was performed without the iceberg model but including, as an external forcing, a monthy climatology of iceberg freshwater flux. This climatology (available 305 in Supplementary Material) has been computed from the monthly means of the ICBT simulation (see section 4.1)

\section{Model evaluation}

\subsection{Ocean/sea ice model}

Figure 3 shows the comparison of the modelled sea ice with observations. 310 Modelled SIC is computed from monthly means of ICBT simulation after spinup. Observations of sea ice concentration come from NSDIC monthly means for the period 1979-2010. Summer means includes the months from October 
to March, and winter means include months from April to September. ICBT simulation presents more sea ice concentration than observations in the Belling315 shausen Sea in both summer and winter seasons. In summer, sea ice concentration gradients are overall stronger in the model. Besides, simulated summer sea ice is more concentrated in coastal regions of the Atlantic and East Indian sectors and less concentrated in Ross Sea.

The choice of comparing 5-years sea ice means between the different simulations (see section 2.4) is supported by the Figure 4. It shows the standard deviation of the sea ice concentration for the 5-year period after the 9-years spin-up of the ICBT simulation. As shown in Figure 4, the inter annual variability of the sea ice for ICBT simulation is mostly negligible. Large standard deviations are obtained near sea ice margins where year to year variability in SIC is expected to be large.

\subsection{Iceberg model}

\subsubsection{On the model-observations comparison of iceberg presence}

Iceberg model results are compared to ALTIBERG database (Tournadre J., 2015). This database uses the method described in Tournadre et al. (2012)

applied to Jason-I and 9 other satellites covering various time periods from 1992 to 2014. The database provides a single estimate of iceberg volume per grid cell for icebergs of 0.1 to $3 \mathrm{~km}$ in length. It is based on the assumption of a constant iceberg thickness of $247 \mathrm{~m}$. Our study divides this volume by the thickness $(247 \mathrm{~m})$ to obtain the area covered by icebergs in each grid cell.

335 Taking into account grid cell area, we can compute the ratio between the surface covered by icebergs and the ocean surface. This can also be understood as the probability of detecting an iceberg of 0.1 to $3 \mathrm{~km}$ in length in a grid cell. A similar estimation can be made from model results. The total area covered by modelled icebergs is integrated over the same grid as the observations and averaged over a year

Satellite detection of icebergs with radar altimetry is limited by the presence of sea ice. Icebergs can only be detected in sea ice free water and the comparison in regions with high annual sea ice concentration needs to be carefully considered. In order to highlight those sectors, we decided to mask in Figure 5 the 345 regions with sea ice concentration greater than $40 \%$, consistently with the ALTIBERG data treatment. We use observations of mean sea ice cover provided by the NSIDC (Peng et al., 2013) instead of our modelled sea ice concentrations, so as to be more consistent with ALTIBERG detections.

The quantitative comparison of modelled and observed icebergs should be considered with caution because of the specificities of iceberg detections and model settings. On the observation side, the method of Tournadre et al. (2012) only detects small icebergs of up to $3 \mathrm{~km}$ in length. Therefore a significant fraction of the total volume of icebergs, corresponding to icebergs longer than $3 \mathrm{~km}$, is not directly observed with radar altimetry. On the model side, the

355 distribution of iceberg class sizes, which follows Gladstone et al. (2001), assumes that the total annual volume of icebergs is distributed in iceberg classes of up to 
$2.2 \mathrm{~km}$ in length. Given that the thickness of icebergs depends on the category, the model probably overestimates the area covered by small icebergs.

\subsubsection{Qualitative model-observations comparison}

Figure 5 compares the iceberg distribution in the model with observations from the ALTIBERG database (Tournadre J., 2015). It shows the probability of detecting an iceberg in a grid cell of $100 \mathrm{~km}$ x $100 \mathrm{~km}$ over a year following the method described in section 3.2.1. To our knowledge, this is the first qualitative comparison between an iceberg model and the distribution of small icebergs estimated from radar altimetry observations. Patterns of the probability of iceberg presence is overall well reproduced by the model. Indeed, the model correctly computes highly probability of finding icebergs in offshore branches of Antarctic subpolar gyres. The model also reproduces the observed pattern of iceberg presence in the eastward flowing branch of the Weddell Gyre. This pattern is consistent with the observations of Tournadre et al. (2012) (see their Figure 16), whereas most existing iceberg models show major discrepancies in this region (Tournadre et al., 2012). As shown in Figure 6, the presence of icebergs in this region significantly increases the freshwater flux in the Atlantic sector of the Southern Ocean. The improved distribution of icebergs in this region compared with previous studies is likely due to the depth integration of ocean currents as discussed in section 2.2.2

Several differences between the model and observations can also be identified. First, the model suggests a higher probability of iceberg presence in coastal regions compared with observations. It should be noted that most of the ice-

380 berg detections in those coastal sectors have been dismissed from ALTIBERG database based on their sea ice criteria (Tournadre J., 2015). However, synthetic aperture radar images (Wesche and Dierking, 2015) confirm the high presence of small and medium size icebergs trapped in the Antarctic Coastal Current in the Indian and Atlantic sectors. Second, in the model, the Weddell Sea sector presents a relatively larger iceberg-covered area than that found in the Amery or Ross sectors, whereas observations indicate roughly similar probabilities of iceberg presenee in all three Antarctic subpolar gyres. This might indicate that the modelled icebergs are too often trapped within the Antarctic Coastal Current. Indeed, the Antarctic Peninsula is the last escape route for icebergs transiting along the Antarctic Coastal Current. Model misrepresentation of the ability of icebergs to escape coastal regions would therefore result in an increase in iceberg presence north of Weddell Sea. This happens even if, as shown in section 2.2.2, modifications of the iceberg model used in this study tend to decrease the number of icebergs that eventually reach the Antarctic Peninsula. A further misrepresentation of escape routes from coastal regions in the model could also be associated with the representation of iceberg interaction with sea ice, firstly suggested by Lichey and Hellmer (2001), proposed by Hunke and Comeau (2011) and observed by Schodlok et al. (2006). In addition, mesoscale variability in the Antarctic Coastal Current is significant (Stewart and Thompson, 2015), but probably too weak in the model, which may contribute to limit the escape of modelled icebergs from coastal regions. The model also shows a lack of icebergs 
in open ocean waters of the South-East Pacific sector. This could be related to the fact that the model only considers coastal sources of icebergs, whereas observations suggest that large icebergs, which are not represented in the model, break into small icebergs in open ocean waters (Tournadre et al., 2015). These resulting smaller icebergs are then transported by the ACC and reach the west Antarctic Peninsula and the South Atlantic sectors before melting. Neglecting the formation of small icebergs associated with the breaking of large ones is therefore likely to contribute to discrepancies in the South-East Pacific and in the South Atlantic.

\section{Results}

\subsection{Iceberg freshwater flux climatology}

Starting from an initial state free of icebergs, the iceberg model takes about 9 years to reach equilibrium, when iceberg melt water balances the calving flux. ${ }_{415}$ At model equilibrium in ICBT run, the Southern Ocean presents a yearly mean iceberg mass close to $3000 \mathrm{Gt}$, more than twice the iceberg mass input and the melted mass released over one year. This indicates that, on average, model icebergs are transported for more than one year before melting. We find in particular that icebergs usually follow the Antarctic Coastal Current for more ${ }_{420}$ than one year before reaching the open ocean. This is also consistent with recent estimates of the volume of icebergs near the coast of Antarctica (Wesche and Dierking, 2015). Icebergs eventually leave coastal regions carried by offshore flows associated with the three Antarctic subpolar gyres in the Weddell, Ross and Amery sectors (see Figure 5). Such iceberg behaviour in the model is consistent with satellite observations (Tournadre et al., 2012) and was previously reported in the eastern Weddell Sea by Schodlok et al. (2006).

The 11-years climatological estimate of iceberg freshwater release over the Southern Ocean are shown in Figures 6 and 7 . This estimate confirms that iceberg melt over the Southern Ocean is very heterogeneous. For instance, since most of the iceberg mass is concentrated in the Weddell Sea sector, this is where most of the freshwater release occurs. In contrast, iceberg freshwater release appears to be relatively limited in the Bellingshausen Sea, west of the Antarctic Peninsula, most probably because this region is not fed by icebergs flowing from upstream sources along the Antarctic Coastal Current. Our estimate also confirms that iceberg melt exhibits strong seasonality over the Southern Ocean, as suggested by Tournadre et al. (2012) and shown in Figure 7. The freshwater flux is indeed usually below the annual mean value for more than two thirds of the year, with about $43 \%$ of annual fresh-water release occurring from December to February. The strongest seasonality is observed in the Ross Sea and Amundsen Sea sectors in the Pacific, where January and February account for almost half of the net annual freshwater flux. Surprisingly, the seasonality of the freshwater flux in the Indian sector is slightly delayed as compared to other regions, with a maximum flux occurring in February and relatively weak fluxes in December and January. 

increases the amplitude of the seasonal cycle of sea ice volume with larger net production and the melting of sea ice.

The CLIM experiment (see section 2.4) was performed to study the ability of the ocean model to account for the iceberg freshwater fluxes with a reduced

470 CPU cost as compared to ICBT simulation. For instance, the first year after spin-up takes $47 \%$ less CPU time for CLIM than for ICBT. Figure 10 shows the difference in annual mean sea ice concentration and thickness for ICBT and CLIM simulations. It considers the first 5 years after 9 years of spin up. This result reveals strong similarities in the solution obtained when an external 475 forcing is applied at the ocean surface instead of explicitly solving the icebergs dynamics and thermodynamics. This result shows that most of the impact on the sea ice can be captured with the inexpensive approach applied for the CLIM simulation. Differences obtained in most of the Southern Ocean are indeed negligible compared to the differences between ICBT and CTR simulations (see

480 Figure 8).

\section{Discussion of the impact of icebergs on sea ice and ocean surface}

Freshwater fluxes at the ocean surface directly affect surface salinity, ocean stratification and mixed layer depth through changes in bouyancy fluxes at the ocean surface. These changes in surface properties can also indirectly affect sea surface temperature (SST) and sea ice cover (as it is shown in section 4.2). Two important mechanisms can be expected to play a role in the response of Antarctic sea ice to iceberg freshwater release. Firstly, during fall and winter months, when the atmosphere extracts heat from the ocean, a freshening 
of ocean surfaces enhances thermohaline stratification, thereby weakening the rate of convective overturning and therefore the supply of heat to the surface layers from deeper layers. This leads to an increase in net sea ice production because the heat supply from the deep ocean no longer limits sea ice production (Marsland and Wolff, 2001). Secondly, a freshening of the ocean surface also contributes to create shallower mixed layers, thus decreasing the effective heat capacity of ocean surface layers. Ocean surface layers are then more sensitive to air-sea heat fluxes. Under a positive air-sea downward heat flux (e.g. during the melting season), the ocean surface receives more heat, thereby accelerating sea ice melt. Increased sea ice production with icebergs over most of the Southern Ocean is consistent with the mechanism involving the reduction of 500 convective overturning in winter described by Marsland and Wolff (2001). For instance, iceberg freshwater release significantly reduces convective oyerturning in the Weddell Sea, delaying the seasonal opening of Maud Rise Polynia and increasing annual mean sea ice cover in this region. In addition, the model indicates that summer mixed layers (not shown) are shallower with icebergs, consistently with a reduction in the effective heat capacity of ocean surface layers. One could expect that the reduction in heat capacity in ICBT simulation would drive a surface warming during summer as compared to CTR simulation. On the contrary, model SST in the seasonal ice zone are usually considerably colder $\left(0.5-1^{\circ} \mathrm{C}\right)$ with icebergs (see Figure 11$)$. This is probably related to the difference in winter sea ice concentration and thickness between ICBT and CTR, Changes in winter sea ice concentration and thickness may cool the SST by two mechanisms: Firstly, the extra insulation exerted by the thicker or more concentrated sea ice layer may reduce the net heat flux received by the ocean surface layer in spring and summer. Secondly, larger latent heat fluxes are required to melt the extra sea ice volume of the ICBT simulation. Both mechanisms seem to notably compensate the effect of changes in heat capacity.

As noted above, modelled iceberg melt is relatively limited in the Bellingshausen Sea west of the Antarctic Peninsula, but the response of the modelled sea ice to this extra freshwater is significant and somewhat unexpected. In contrast with most of the Southern Ocean, sea ice tends to be thinner with icebergs in this region while sea ice concentration is essentially unchanged (see Figure 8). In addition, SSTs are found to be significantly warmer in summer upstream of the Bellingshausen Sea along the Antarctic Peninsula (see Figure 11). This suggests that the equilibrium state reached after spin-up in the Bellingshausen Sea may be affected by changes in heat transport by the Antarctic Coastal Current. In the model, the lateral supply of warmer water may affect the formation of sea ice in the Bellingshausen Sea so that the ocean/sea ice system eventually reaches an equilibrium state with thinner sea ice over the entire annual cycle. What drives the warming of surface layers upstream is not clear yet, but this warming could be associated with changes in effective heat capacity of ocean surface layers in coastal regions along the Antarctic Peninsula. Other processes in the model, as for instance changes in the convective supply of heat to the surface could also contribute to the unexpected response of simulated sea ice properties in the Bellingshausen Sea. But further analysis would be needed to 
disentangle the mechanisms involved. In conclusion, the response in terms of modelled sea ice volume in the Bellingshausen Sea illustrates how icebergs can affect ocean surface properties through a range of physical processes. Indeed, the Bellingshausen sector presents the only discrepancies between ICBT and CLIM simulations (see Figure 10). The forced simulation (CLIM) produces even thinner sea ice than ICBT and CTR. The three simulations notably differ in their sea ice thickness solution in the Bellingshausen sector. However, the icebergs fluxes in the sector seems to be weaker than what the observations suggests (see Figure 5), and the discussed mechanism producing sea ice thinning should not be considered as a realistic climate feature in the sector. Instead, the Bellingshausen Sea in the model is an example which illustrates how, under specific conditions, the way icebergs fluxes are represented in the ocean models may be crucial to model sea ice.

\section{Conclusions}

In this paper, we have studied the climatological distribution of iceberg melt over the Southern Ocean and its impact on Antarctic sea ice and ocean surface properties. To do this, we have used a Lagrangian iceberg model (Marsh et al., 2015) coupled with a global, eddy-permitting ocean sea ice model configuration (NEMO-ORCA025). The Lagrangian iceberg model has been modified in order to explicitly take into account the influence of ocean current and temperature

555 vertical profiles. Ocean currents integrated along the iceberg vertical profile are shown to notably impact the trajectories of icebergs crossing the subpolar gyres in the Ross, Amery and Weddell Seas. The model is forced with recent estimates of calving rates and melt rates for the Antarctica Ice Sheet (Depoorter et al., 2013).

${ }_{560}$ The distribution of Antarctic icebergs in the model is shown to be broadly consistent with satellite observations of small icebergs from radar altimetry. We have presented the first comparison of the probability of iceberg detection obtained from radar altimetry with that from an iceberg model. This comparison makes it possible to identify limitations of current Lagrangian iceberg models

For instance, modelled icebergs seem to be too confined in the Antarctic Counter Current, which impacts the equatorward transport of icebergs through the Ross and Amery subpolar gyres. In addition, modelled iceberg trajectories seem too short in the model, especially in the Pacific sector where observations suggest that iceberg are transported further east. Improving the representation of icebergs/sea ice interaction may also improve simulation results, either by producing more export of icebergs out of the Antarctic Counter Current following the drift of the sea ice pack, or by fastening iceberg close to coast within fast sea ice. Additionally, a higher ocean model resolution and the representation of the synoptic component of the wind forcing could help icebergs escaping the Antarctic Counter Current. Finally, accounting for small icebergs associated with the fracturing of large tabular, could result in trajectories extending further east and might lead to a better agreement between the model and the 
altimetry observations. This could be reproduced in the model by adding offshore calving sources in the model according to a probabilistic estimation of the 580 tabular iceberg fracturing.

Iceberg melt over the Southern Ocean is found to show a significant seasonality and to be mostly concentrated in offshore flowing branches of Antarctic subpolar gyres. A large fraction of the total iceberg melt is found to occur in the South Atlantic sector of the Southern Ocean. The freshwater release is found to 585 be strongly seasonal in the Ross Sea and the Amundsen Sea where almost half of the freshwater release occurs in January and February. The monthly climatology of iceberg melt over the Southern Ocean is provided as Supplementary Material.

Iceberg melt is shown to substantially increase sea ice concentration and thickness over most of the Southern Ocean, except in the Bellingshausen Sea where iceberg melt decreases sea ice thickness in the model. As suggested by previous studies, in most of the Southern Ocean, iceberg melt increases sea ice production in autumn and winter because it reduces convective overturning, thus limiting the heat supply from the deep ocean to the surface. In contrast, iceberg melt results in thinner sea ice in the Bellingshausen Sea, probably because of the advection of warmer waters flowing along the Antarctic Coastal Current.

The extra computational cost of running an explicit iceberg model can be drastically reduced by forcing the ocean model with a monthly climatology of iceberg melt. Figure 10 shows that this inexpensive simulation strategy succeeds in capturing the essential aspects of the respønse of sea ice to freshwater release in a climatological forced oceansimulation. Whether this result still holds with an inter-annually varying atmospheric forcing needs to be further investigated. Such a forcing strategy could arguably be adopted for forced ocean simulations and possibly adapted to climate models. For climate simulations, latent heat exchanges due to iceberg melt would need to be recalculated from the freshwater fluxes in order for the model to conserve energy.

\section{Appendix: Modified equations of the NEMO-ICB Lagrangian iceberg model}

Interested reader may refer to Martin and Adcroft (2010) for a thorough 610 description of the dynamics and thermodynamics of the iceberg model. We only describe here our modifications and the corresponding changes in the original model equations.

The parametrized dynamics of the iceberg model from Martin and Adcroft (2010) which are based on Bigg et al. (1997), depend on the sea surface velocity.

${ }_{615}$ In this work we consider the following depth-integrated ocean velocity:

$$
\overrightarrow{v_{m}}=\frac{\int_{-\min \left(H_{b a t}, H_{i c b}\right)}^{0} \overrightarrow{v_{o}}(h) d h}{H_{i c b}}
$$

where $H_{b a t}$ is the bathymetry depth at the grid point, $H_{i c b}$ is the submerged part of the iceberg thickness, $d h$ is the differential of depth, $\overrightarrow{v_{o}}(h)$ is the ocean 
velocity depending on the depth and $\vec{m}(h)$ is the resulting depth-integrated ocean velocity.

Our version of NEMO-ICB model uses the equations A.2a A.2b and A.2c from Martin and Adcroft (2010) applying $\overrightarrow{v_{m}}(h)$ instead of the sea surface velocity.

We also modify the equations of the parametrization of basal turbulence and buoyant convection melt rates (see equations A.7 and A.9 from Martin and ${ }_{625}$ Adcroft (2010)) as follows:

$$
M_{b}=0.58\left|\vec{v}-\overrightarrow{v_{b}}\right|^{0.8} \frac{\tilde{T}_{b}-\tilde{T}}{L^{0.2}}
$$

with $\overrightarrow{v_{b}}=v_{\text {bat }}$ and $\tilde{T}_{b}=\tilde{T}_{b a t}$ whenever $H_{i c b}>H_{b a t}$, where $\vec{v}$ is the iceberg velocity, $\overrightarrow{v_{b}}$ is the velocity of the ocean at the base of the iceberg, $v_{b a t}$ is the bottom ocean velocity (i.e. at sea floor depth), $\tilde{T}_{b}$ is the ocean temperature at the base of the iceberg, $\tilde{T}_{b a t}$ is the bottom ocean temperature, $L$ is the iceberg horizontal length, and $M_{b}$ is the resulting basal turbulence melt rate.

Finally, the buoyant convection melt rate is integrated over the depth of the iceberg as follows:

$$
M_{v}=\int_{-H_{i c b}}^{0}\left(7.62 \times 10^{-3} \tilde{T}_{o}(h)+1.29 \times 10^{-3} \tilde{T}_{o}^{2}(h)\right) d h
$$

with $\tilde{T}_{o}(h)=\tilde{T}_{b a t}$ whenever $h>H_{b a t}$, where $\tilde{T}_{o}(h)$ is the ocean temperature at depth $h$ and $M_{v}$ is the resulting buoyant convection melt rate.

635

\section{Acknowledgments}

We would like to thank Jean Marc Molines for his invaluable help with model configuration. Numerical simulations were performed on IDRIS supercomputers (Saclay, France). The study was partially funded by the French National Research Agency (ANR) under the SUMER (Blanc SIMI 6) 2012 project, ref640 erenced as ANR-12-BS06-0018. NCJ is an Associate Investigator with the ARCCSS (ARC Centre of Excellence for Climate System Science). Finally, we woułd like to thank the three anonymous reviewers and the editor Stephen Griffies for their helpful and constructive contribution to this work.

\section{References}

Bigg, G. R., Wadley, M. R., Stevens, D. P., Johnson, J. A., 1997. Modelling the dynamics and thermodynamics of icebergs. Cold Regions Science and Technology 26 (2), 113-135.

Bintanja, R., Van Oldenborgh, G., Drijfhout, S., Wouters, B., Katsman, C., 2013. Important role for ocean warming and increased ice-shelf melt in antarc650 tic sea-ice expansion. Nature Geoscience 6 (5), 376-379. 
Comiso, J. C., Nishio, F., Feb. 2008. Trends in the sea-ice cover using enhanced and compatible AMSR-E, SSM/I, and SMMR data. Journal of Geophysical Research: Oceans 113 (C2), C02S07.

URL http://onlinelibrary.wiley.com.biblioplanets.gate.inist.fr/ doi/10.1029/2007JC004257/abstract

Dee, D. P., Uppala, S. M., Simmons, A. J., Berrisford, P., Poli, P., Kobayashi, S., Andrae, U., Balmaseda, M. A., Balsamo, G., Bauer, P., Bechtold, P., Beljaars, A. C. M., van de Berg, L., Bidlot, J., Bormann, N., Delsol, C., Dragani, R. Fuentes, M., Geer, A. J., Haimberger, L., Healy, S. B., Hersbach, H., Hlm, E. V., Isaksen, L., Kllberg, P., Khler, M., Matricardi, M., MeNally, A.P., Monge-Sanz, B. M., Morcrette, J.-J., Park, B.-K., Peubey, C., de Rosnay, P., Tavolato, C., Thpaut, J.-N., Vitart, F., Apr. 2011. The ERA-Interim reanalysis: configuration and performance of the data assimilation system. Quarterly Journal of the Royal Meteorological Society 137 (656), 553-597. URL http://doi.wiley.com/10.1002/qj.828

Depoorter, M., Bamber, J., Griggs, J., Lenaerts, J., Ligtenberg, S., van den Broeke, M., Moholdt, G., 2013. Calving fluxes and basal melt rates of antarctic ice-shelves. Nature.

Eisenman, I., Meier, W. N., Norris, J. R., Jul. 2014. A spurious jump in the satellite record: has Antarctic sea-ice expansion been overestimated? The Cryosphere 8 (4), 1289-1296.

URL http://www. the-cryosphere. net/8/1289/2014/

Fan, T., Deser, C., Schneider, D. P., 2014. Recent antarctic sea-ice trends in the context of southern ocean surface climate variations since 1950. Geophysical Research Letters 41,(7), 2419-2426.

Fichefet, T., Morales Maqueda, M. A. M., Jun. 1997. Sensitivity of a global sea-ice model to the treatment of ice thermodynamics and dynamics. Journal of Geophysical Research: Oceans 102 (C6), 12609-12646.

URL http://onlinelibrary.wiley.com.biblioplanets.gate.inist.fr/ doi/10.1029/97JC00480/abstract

Gagne, M.-E., Gillett, N. P., Fyfe, J. C., Jan. 2015. Observed and simulated changes in Antarctic sea-ice extent over the past 50 years. Geophysical Research Letters 42 (1), 2014GL062231.

URL http: //onlinelibrary.wiley.com.biblioplanets.gate.inist.fr/ doi/10.1002/2014GL062231/abstract

Gladstone, R. M., Bigg, G. R., Nicholls, K. W., 2001. Iceberg trajectory modeling and meltwater injection in the southern ocean. Journal of Geophysical Research: Oceans (1978-2012) 106 (C9), 19903-19915.

Goosse, H., Zunz, V., Mar. 2014. Decadal trends in the Antarctic sea-ice extent ultimately controlled by iceocean feedback. The Cryosphere 8 (2), 453-470. URL http://www . the-cryosphere.net/8/453/2014/ 
Grégorio, S., Penduff, T., Sérazin, G., Molines, J.-M., Barnier, B., Hirschi, J., 2015. Intrinsic variability of the atlantic meridional overturning circulation at interannual-to-multidecadal time scales. Journal of Physical Oceanography 45 (7), 1929-1946.

Griffies, S. M., Biastoch, A., Böning, C., Bryan, F., Danabasoglu, G., Chassignet, E. P., England, M. H., Gerdes, R., Haak, H., Hallberg, R. W., et al., 2009. Coordinated ocean-ice reference experiments (cores). Ocean Modelling 26 (1), 1-46.

700 Holland, P. R., Bruneau, N., Enright, C., Losch, M., Kurtz, N. T., Kwok, R., 2014. Modeled trends in antarctic sea-ice thickness. Journal of Climate 27 (10), 3784-3801.

Holland, P. R., Kwok, R., Dec. 2012. Wind-driven trends in Antarctic sea-ice drift. Nature Geoscience 5 (12), 872-875.

705 URL http://www.nature.com.biblioplanets.gate.inist.fr/ngeo/ journal/v5/n12/full/ngeo1627.html

Hunke, E. C., Comeau, D., 2011. Sea-ice and iceberg dynamic interaction. Journal of Geophysical Research: Oceans (1978-2012) 116 (C5).

Jacka, T. H., Giles, A. B., 2007. Antarctic iceberg distribution and dissolution from ship-based observations. Journal of Glaciology 53 (182), 341-356.

Jongma, J. I., Driesschaert, E., Fichefet, T., Goosse, H., Renssen, H., 2009. The effect of dynamic-thermodynamic icebergs on the southern ocean climate in a three-dimensional model. Ocean Modelling 26 (1), 104-113.

Lefebvre, W., Goosse, H., Timmermann, R., Fichefet, T., 2004. Influence of the southern annular mode on the sea-ice-ocean system. Journal of Geophysical Research: Oceans (1978-2012) 109 (C9).

Lenn, Y.-D., Chereskin, T. K., 2009. Observations of ekman currents in the southern ocean. Journal of Physical Oceanography 39 (3), 768-779.

Lichey, C., Hellmer, H. H., 2001. Modeling giant-iceberg drift under the influence 720 of sea ice in the weddell sea, antarctica. Journal of Glaciology 47 (158), 452460.

Liu, J., Curry, J. A., Martinson, D. G., 2004. Interpretation of recent antarctic sea-ice variability. Geophysical Research Letters 31 (2).

Madec, G., 2014. NEMO ocean engine, institut pierre-simon laplace (ipsl) Edition. No. 27 in Note du Ple de modlisation.

Marsh, R., Ivchenko, V. O., Skliris, N., Alderson, S., Bigg, G. R., Madec, G., Blaker, A. T., Aksenov, Y., Sinha, B., Coward, A. C., Le Sommer, J., Merino, N., Zalesny, V. B., May 2015. NEMO-ICB (v1.0): interactive icebergs in the NEMO ocean model globally configured at eddy-permitting resolution. 
Geosci. Model Dev. 8 (5), 1547-1562.

URL http://www.geosci-model-dev.net/8/1547/2015/

Marsland, S., Wolff, J.-O., 2001. On the sensitivity of southern ocean sea-ice to the surface freshwater flux: a model study. Journal of Geophysical Research: Oceans (1978-2012) 106 (C2), 2723-2741.

Martin, T., Adcroft, A., 2010. Parameterizing the fresh-water flux from land ice to ocean with interactive icebergs in a coupled climate model. Ocean Modelling 34 (3), 111-124.

Parkinson, C. L., Cavalieri, D. J., Aug. 2012. Antarctic sea-ice variability and trends, 19792010. The Cryosphere 6 (4), 871-880. URL http://www. the-cryosphere.net/6/871/2012/

Penduff, T., Juza, M., Barnier, B., Zika, J., Dewar, W. K., Treguier, A.-M., Molines, J.-M., Audiffren, N., 2011. Sea level expression of intrinsic and forced ocean variabilities at interannual time scales. Journal of Climate 24 (21), $5652-5670$.

745 Peng, G., Meier, W., Scott, D., Savoie, M., 2013. A long-term and reproducible passive microwave sea ice concentration data record for climate studies and monitoring. Earth System Science Data 5 (2), 311-318.

Polvani, L. M., Smith, K. L., Jun. 2013. Can natural variability explain observed Antarctic sea-ice trends? New modeling evidence from CMIP5. Geophysical

$750 \quad$ Research Letters 40 (12), 3195-3199.

URL http://onlinelibrary.wiley.com.biblioplanets.gate.inist.fr/ doi/10.1002/grl.50578/abstract

Rignot, E., Bamber, J. L., Van Den Broeke, M. R., Davis, C., Li, Y., Van De Berg, W. J., Van Meijgaard, E., 2008. Recent antarctic ice mass loss from

755 radar interferometry and regional climate modelling. Nature Geoscience 1 (2), $106-110$.

Rignot, E., Jacobs, S., Mouginot, J., Scheuchl, B., 2013. Ice-shelf melting around antarctica. Scíence 341 (6143), 266-270.

Rignot, E., Jacobs, S. S., 2002. Rapid bottom melting widespread near antarctic ice sheet grounding lines. Science 296 (5575), 2020-2023.

Schodlok, M., Hellmer, H., Rohardt, G., Fahrbach, E., 2006. Weddell sea iceberg drift: Five years of observations. Journal of Geophysical Research: Oceans (1978-2012) 111 (C6).

Shepherd, A., Ivins, E. R., Geruo, A., Barletta, V. R., Bentley, M. J., Bettadpur, S., Briggs, K. H., Bromwich, D. H., Forsberg, R., Galin, N., et al., 2012. A reconciled estimate of ice-sheet mass balance. Science 338 (6111), 1183-1189. 
Silva, T., Bigg, G., Nicholls, K., 2006. Contribution of giant icebergs to the southern ocean freshwater flux. Journal of Geophysical Research: Oceans (1978-2012) 111 (C3).

770 Stammerjohn, S. E., Martinson, D. G., Smith, R. C., Yuan, X., Rind, D., Mar. 2008. Trends in Antarctic annual sea-ice retreat and advance and their relation to El NioSouthern Oscillation and Southern Annular Mode variability. Journal of Geophysical Research 113 (C3).

URL http://www .agu.org/pubs/crossref/2008/2007JC004269.shtml

775 Stewart, A. L., Thompson, A. F., 2015. Eddy-mediated transport of warm circumpolar deep water across the antarctic shelf break. Geophysical Research Letters 42 (2), 432-440.

Swart, N., Fyfe, J., 2013. The influence of recent antarctic ice sheet retreat on simulated sea-ice area trends. Geophysical Research Letters 40 (16), 4328 4332 .

Tournadre, J., Bouhier, N., Girard-Ardhuin, F.,Rmy, F., 2015. Large icebergs characteristics from altimeter waveforms analysis. Journal of Geophysical Research: Oceans 120 (3), 1954-1974.

Tournadre, J., Girard-Ardhuin, F., Legrésy, B., 2012. Antarctic icebergs distributions, 2002-2010. Journal of Geophysical Research: Oceans (1978-2012) 117 (C05004).

Tournadre J., N. Bouhier, F. G.-A. a. F. R., 2015. Antarctic icebergs distributions 1992-2014. J. Geophys. Res.

Turner, J., Comiso, J. C., Marshall, G. J., Lachlan-Cope, T. A., Bracegirdle, T., Maksym, T., Merèdith, M. P., Wang, Z., Orr, A., Apr. 2009. Non-annular atmospheric circulation change induced by stratospheric ozone depletion and its role in the recent increase of Antarctic sea-ice extent. Geophysical Research Letters 36 (8), L08502.

URL http://onlinelibrary.wiley.com.biblioplanets.gate.inist.fr/ doi/10.1029/2009GL037524/abstract

Turner, J., Hosking, J. S., Bracegirdle, T. J., Marshall, G. J., Phillips, T., 2015. Recent changes in antarctic sea ice. Philosophical Transactions of the Royal Society of London A: Mathematical, Physical and Engineering Sciences 373 (2045), 20140163.

Uotila, P., Holland, P. R., Vihma, T., Marsland, S. J., Kimura, N., 2014. Is realistic antarctic sea-ice extent in climate models the result of excessive ice drift? Ocean Modelling 79, 33-42.

van den Berk, J., Drijfhout, S., 2014. A realistic freshwater forcing protocol for ocean-coupled climate models. Ocean Modelling 81, 36-48. 
805 Wesche, C., Dierking, W., 2015. Near-coastal circum-antarctic iceberg size distributions determined from synthetic aperture radar images. Remote Sensing of Environment 156, 561-569.

Zhang, J., 2007. Increasing antarctic sea-ice under warming atmospheric and oceanic conditions. Journal of Climate 20 (11), 2515-2529. 


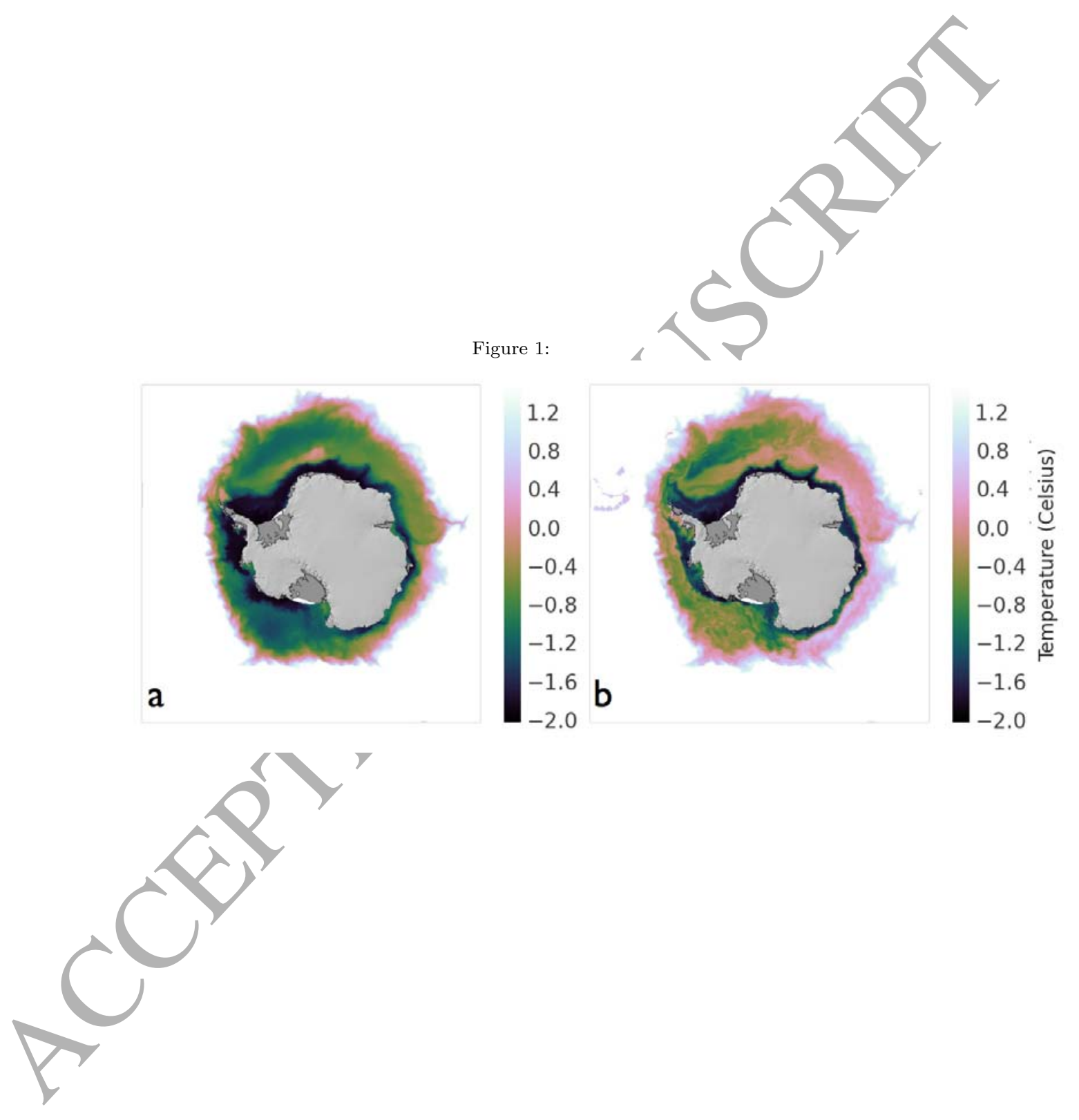



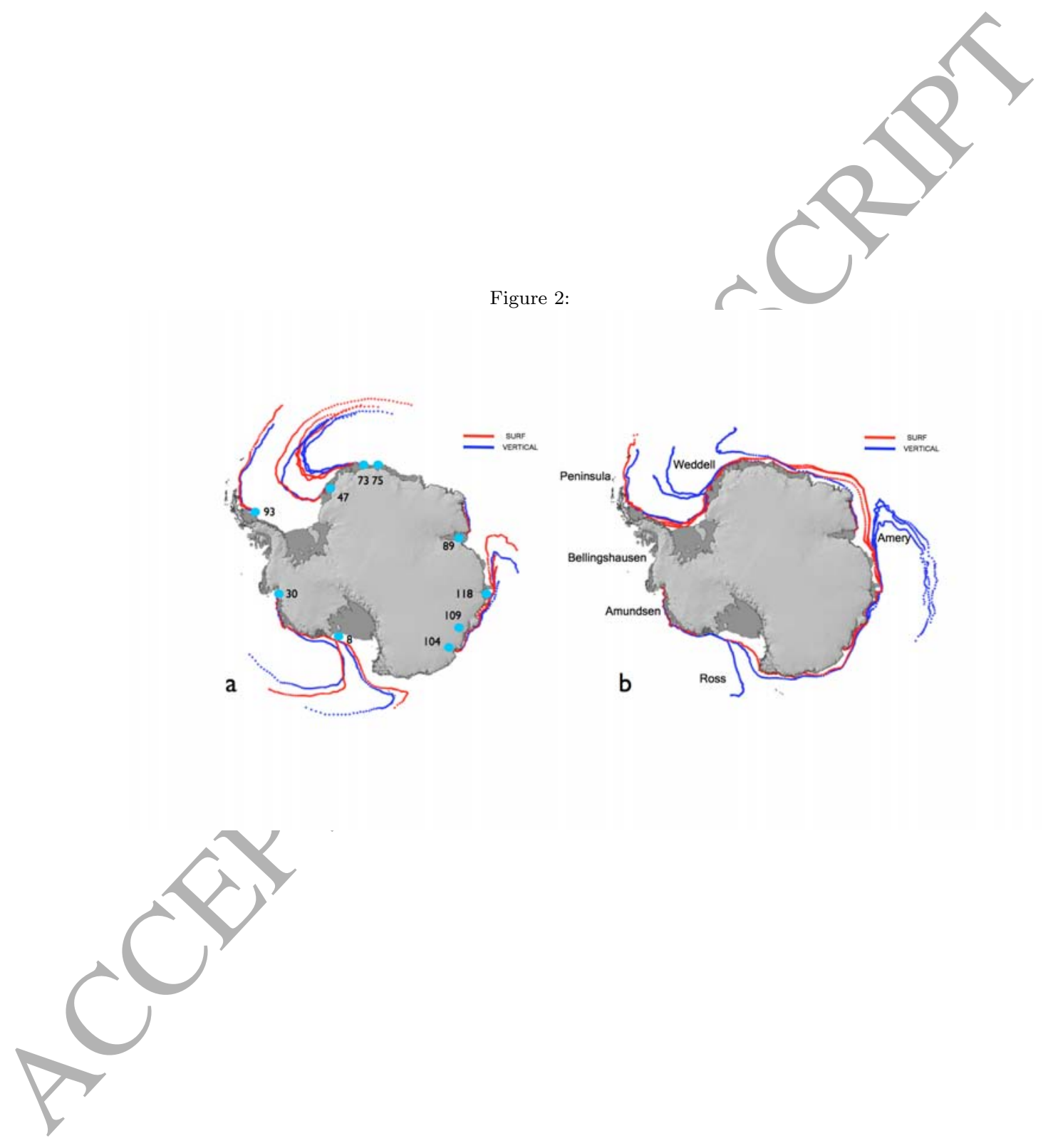


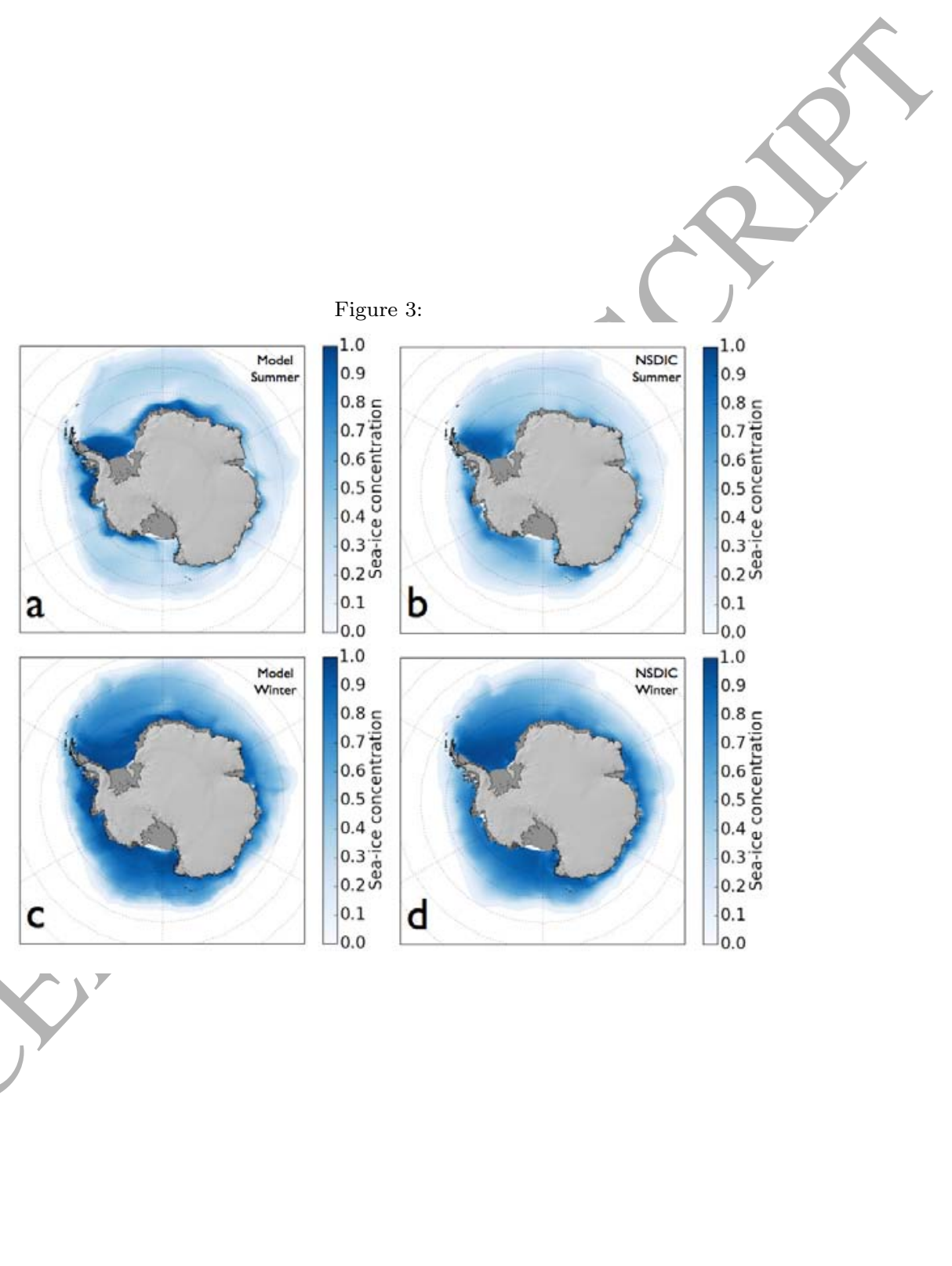


Figure 4:
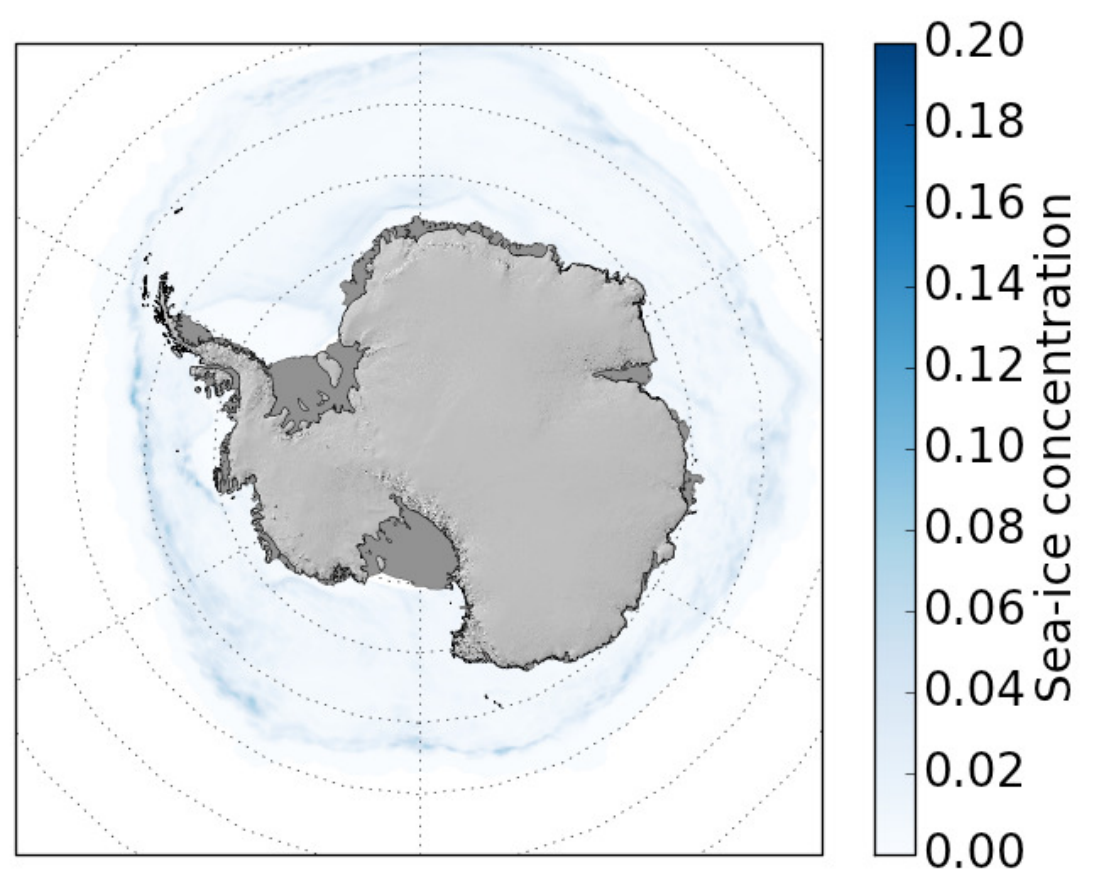


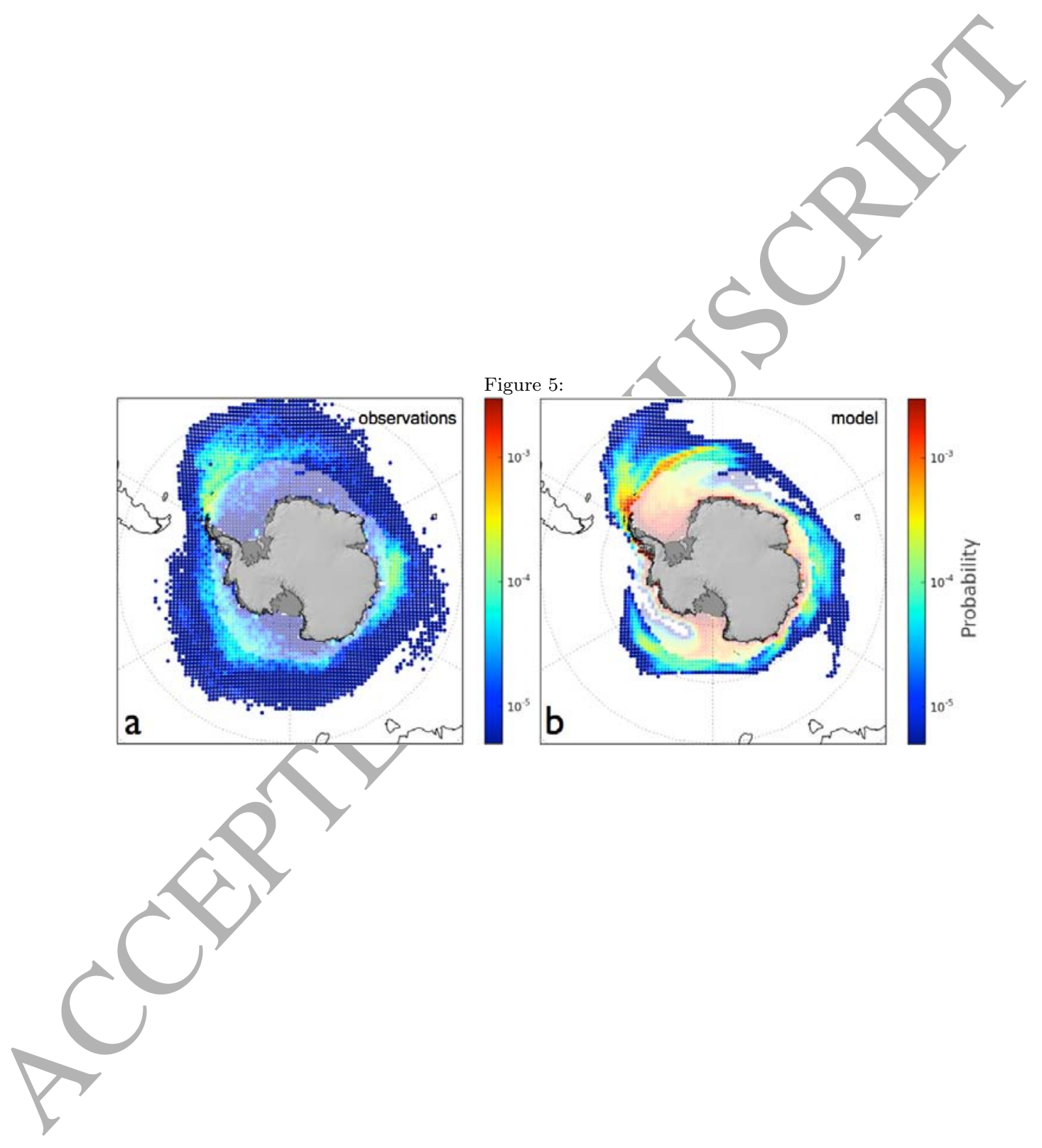




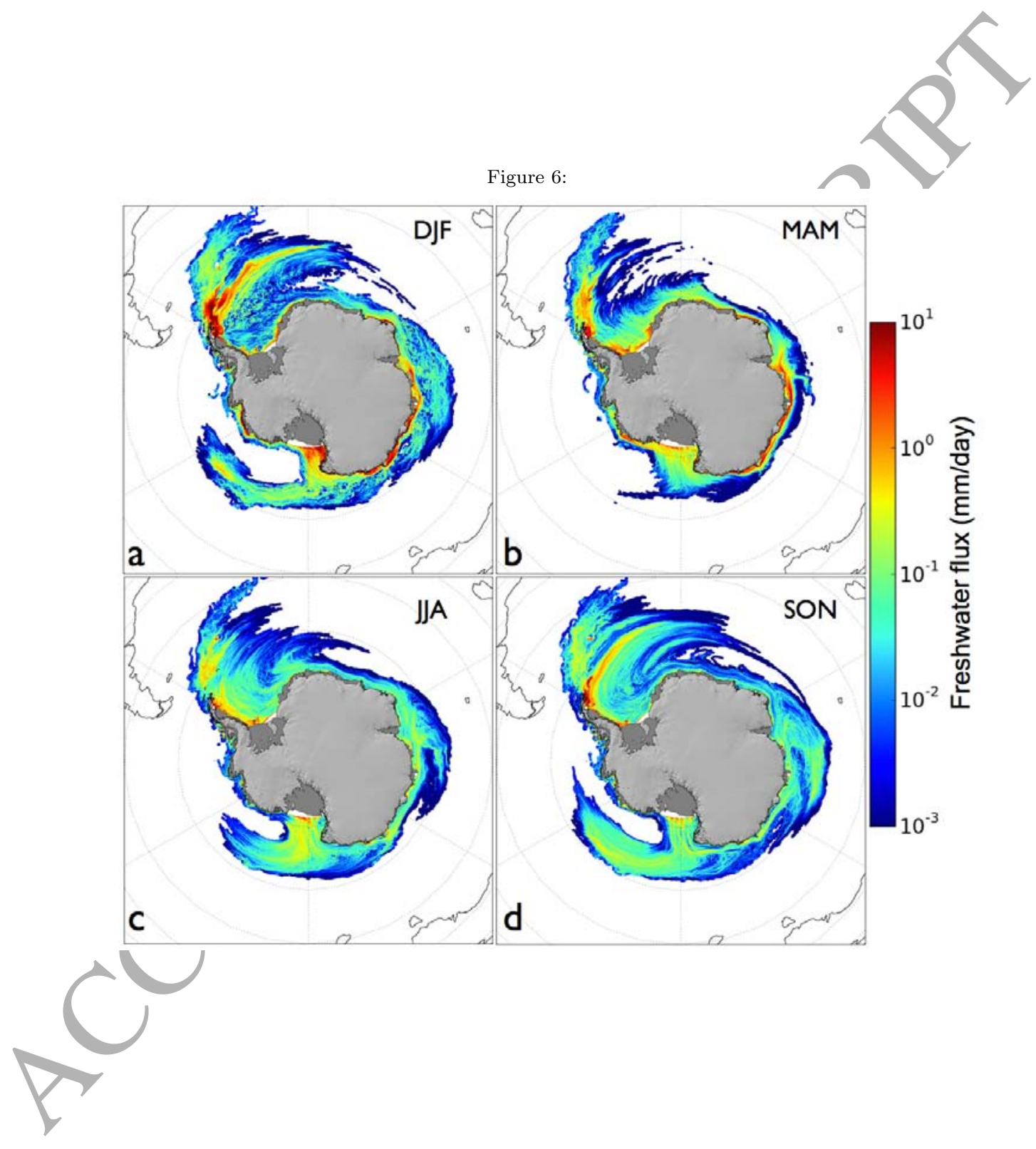


Figure 7:
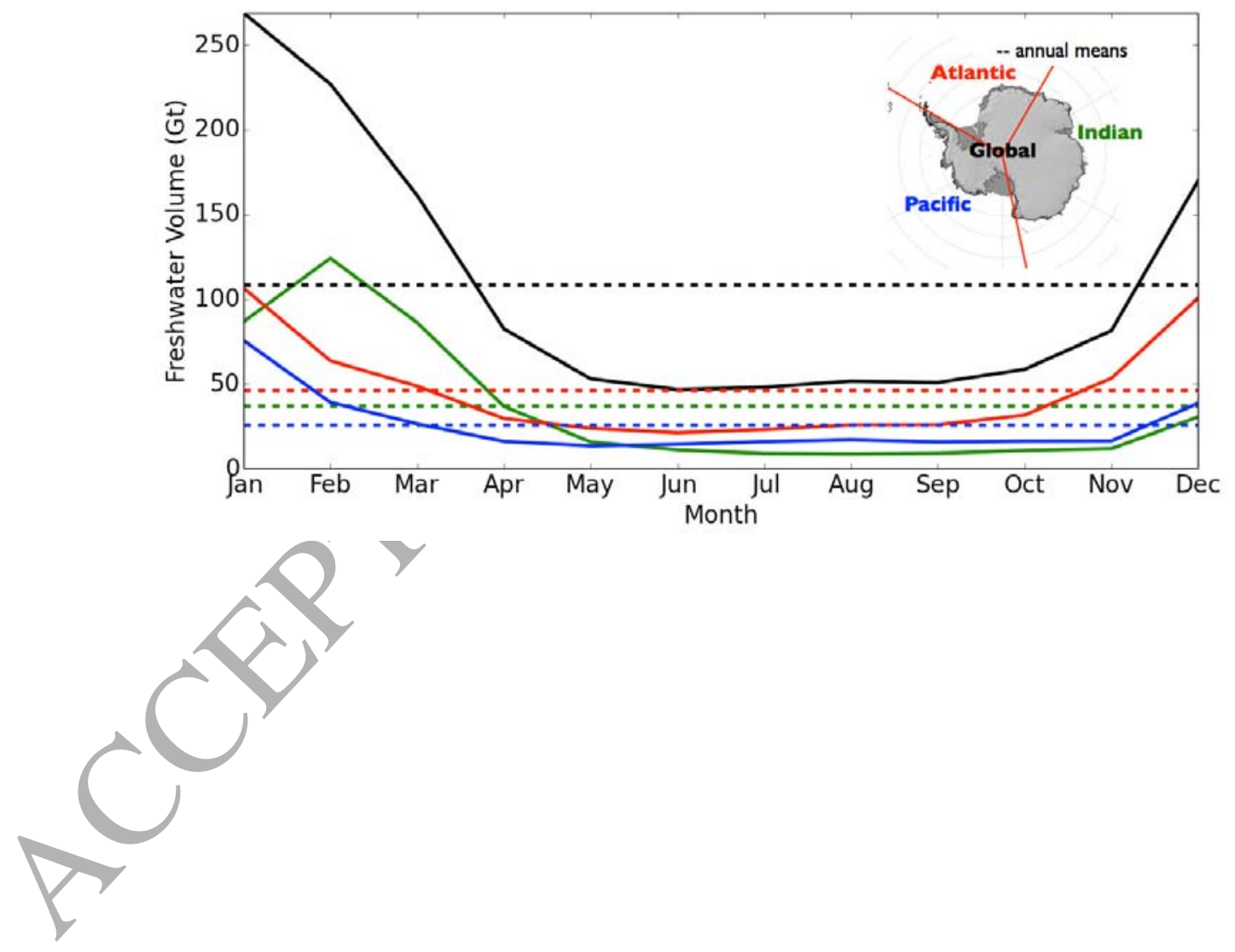


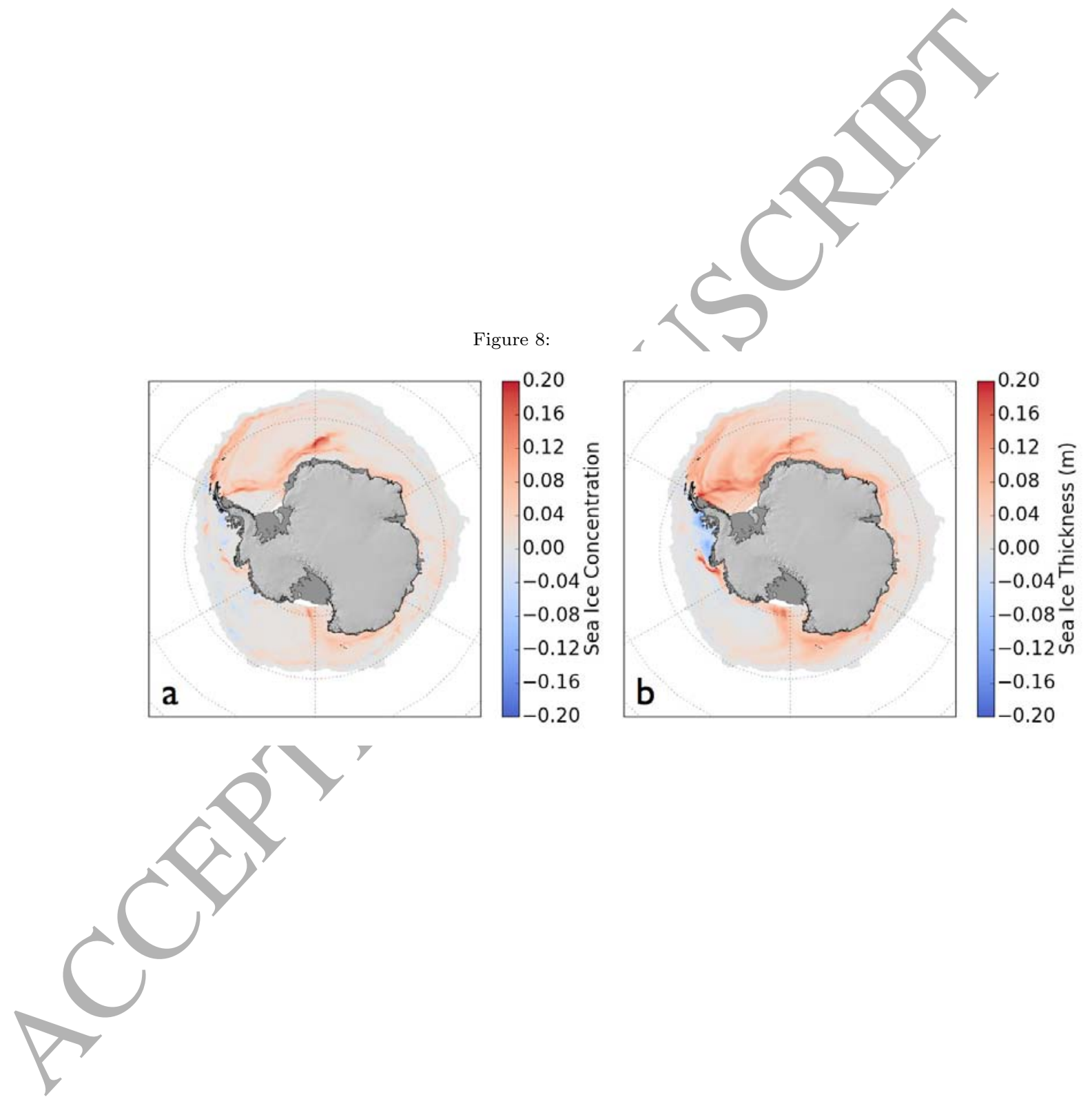



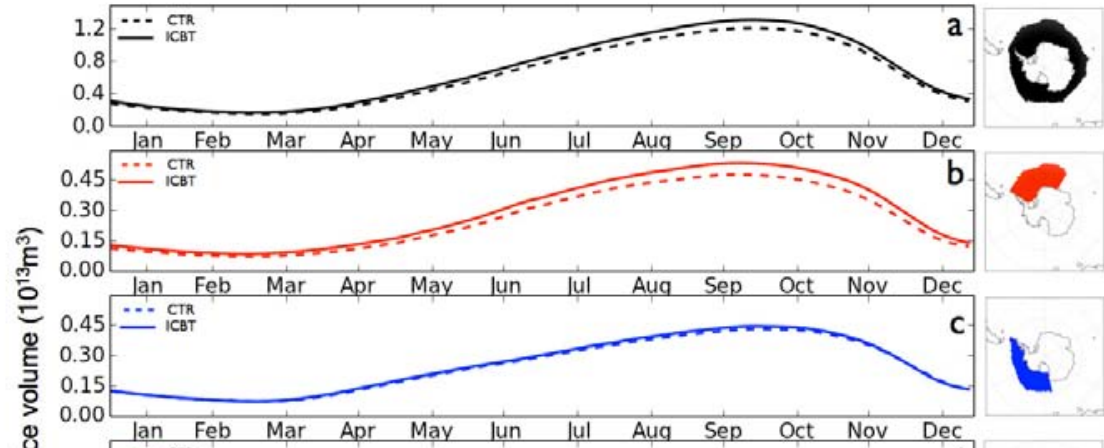

\& lan Feb Mar Apr May lun lul Auq Sep Oct Nov Dec
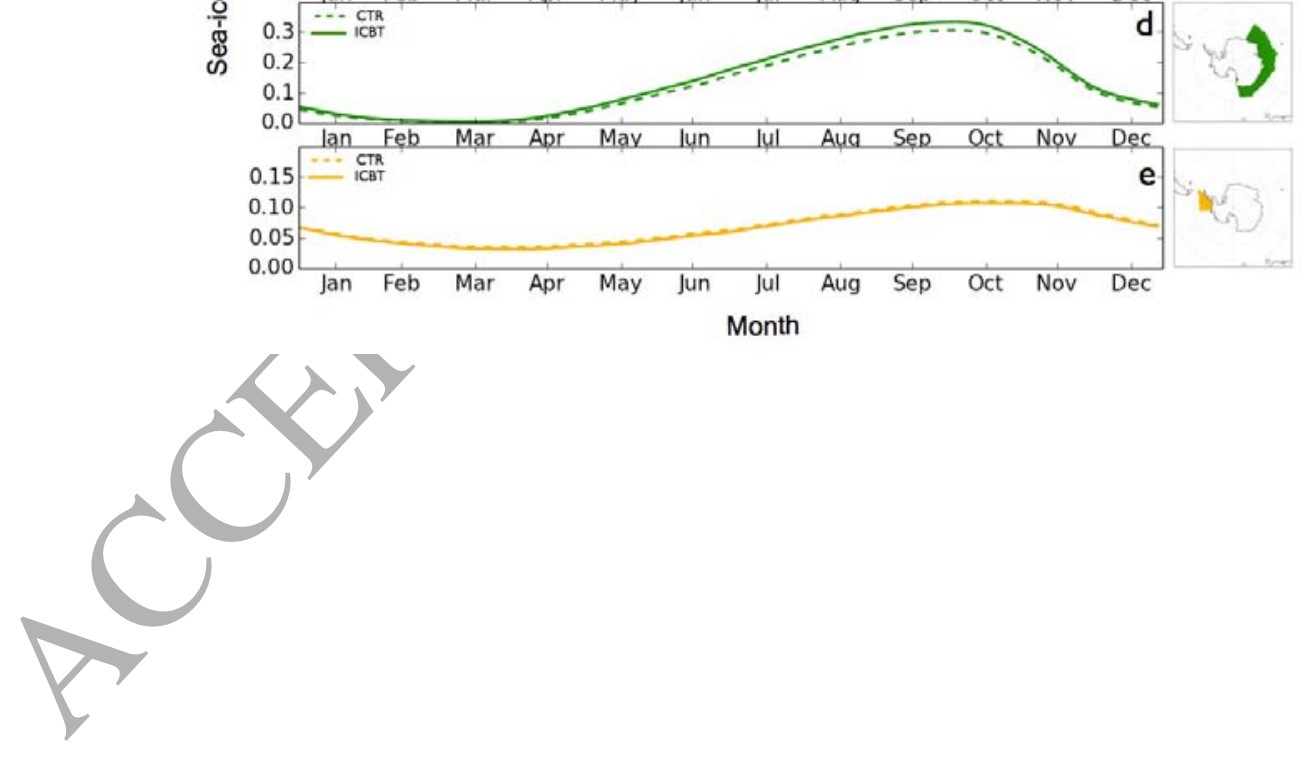

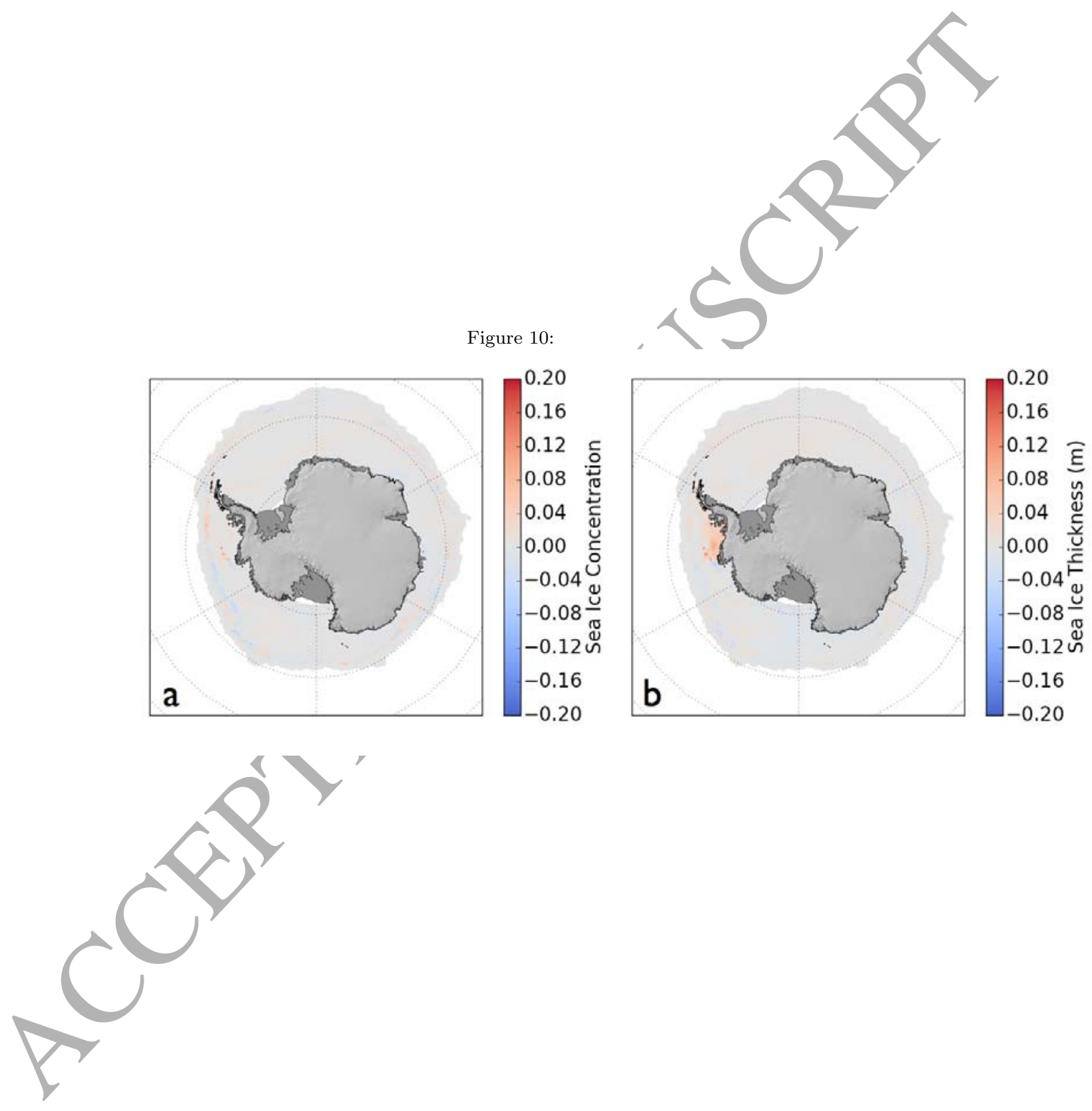
Figure 11:

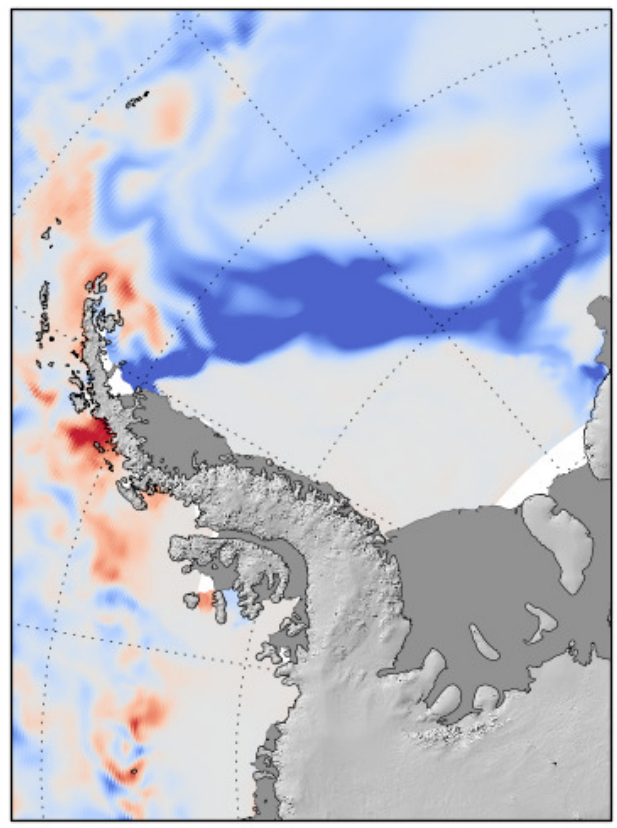

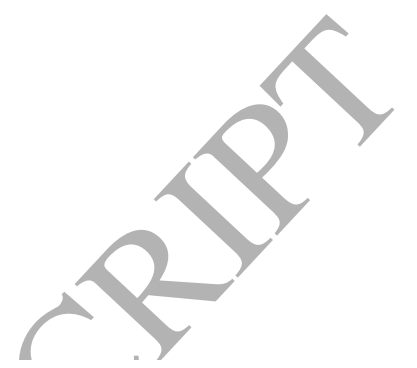

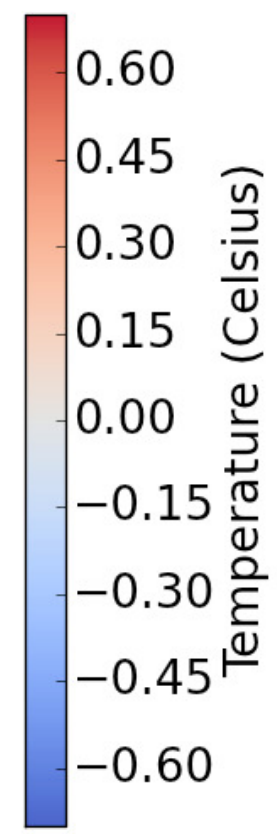

